\title{
ERS technical standard on bronchial challenge testing: general considerations and performance of methacholine challenge tests
}

\author{
Allan L. Coates ${ }^{1}$, Jack Wanger ${ }^{2}$, Donald W. Cockcroft ${ }^{3}$, Bruce H. Culver ${ }^{4}$ and \\ the Bronchoprovocation Testing Task Force: Kai-Håkon Carlsen ${ }^{5}$, \\ Zuzana Diamant ${ }^{6,7}$, Gail Gauvreau ${ }^{8}$, Graham L. Hall' , Teal S. Hallstrand ${ }^{4}$ \\ Ildiko Horvath ${ }^{10}$, Frans H.C. de Jongh ${ }^{11}$, Guy Joos ${ }^{12}$, David A. Kaminsky ${ }^{13}$, \\ Beth L. Laube ${ }^{14}$, Joerg D. Leuppi ${ }^{15}$ and Peter J. Sterk ${ }^{16}$
}

\begin{abstract}
Affiliations: ${ }^{1}$ Division of Respiratory Medicine, Dept of Pediatrics, Physiology and Experimental Medicine, Research Institute, Hospital for Sick Children, University of Toronto, Toronto, ON, Canada. ${ }^{2}$ Pulmonary Function Testing and Clinical Trials Consultant, Rochester, MN, USA. ${ }^{3}$ Division of Respirology, Critical Care and Sleep Medicine, Royal University Hospital, Saskatoon, SK, Canada. ${ }^{4}$ Division of Pulmonary and Critical Care Medicine, University of Washington, Seattle, WA, USA. ${ }^{5}$ Institute of Clinical Medicine, Oslo, Norway. ${ }^{6}$ Dept of Clinical Pharmacy and Pharmacology and QPS-Netherlands, University Medical Centre Groningen, University of Groningen, Groningen, The Netherlands. ${ }^{7}$ Dept of Respiratory Medicine and Allergology, Lund University, Lund, Sweden. ${ }^{8}$ Division of Respirology, Dept of Medicine, McMaster University, Hamilton, ON, Canada. ${ }^{9}$ Children's Lung Health, Telethon Kids Institute, School of Physiotherapy and Exercise Science, Curtin University and Centre for Child Health Research, University of Western Australia, Perth, Australia. ${ }^{10}$ Dept of Pulmonology, Semmelweis University, Budapest, Hungary. ${ }^{11}$ Dept of Pulmonary Medicine, Medisch Spectrum Twente, Enschede, The Netherlands. ${ }^{12}$ Dept of Respiratory Medicine, University of Ghent, Ghent, Belgium. ${ }^{13}$ Pulmonary and Critical Care, University of Vermont College of Medicine, Burlington, VT, USA. ${ }_{14}^{14}$ Division of Pediatric Pulmonology, Johns Hopkins University School of Medicine, Baltimore, MD, USA. ${ }^{15}$ University Clinic of Medicine, Kantonsspital Baselland, Liestal, Medical Faculty University of Basel, Basel, Switzerland. ${ }^{16} \mathrm{AMC}$ Hospital, University of Amsterdam, Amsterdam, The Netherlands.
\end{abstract}

Correspondence: Allan L. Coates, Division of Respiratory Medicine, Dept of Pediatrics, Physiology and Experimental Medicine, Research Institute, Hospital for Sick Children, 555 University Avenue, Toronto, ON M5R 1S6, Canada. E-mail: allan.coatesdasickkids.ca

@ERSpublications

The new ERS recommendation for methacholine challenge tests will be the provocative dose rather than concentration http://ow.ly/FBe5309yXn2

Cite this article as: Coates AL, Wanger J, Cockcroft DW, et al. ERS technical standard on bronchial challenge testing: general considerations and performance of methacholine challenge tests. Eur Respir J 2017; 49: 1601526 [https://doi.org/10.1183/13993003.01526-2016].

ABSTRACT This international task force report updates general considerations for bronchial challenge testing and the performance of the methacholine challenge test. There are notable changes from prior recommendations in order to accommodate newer delivery devices. Rather than basing the test result upon a methacholine concentration (provocative concentration (PC20) causing a 20\% fall in forced expiratory volume in $\left.1 \mathrm{~s}\left(\mathrm{FEV}_{1}\right)\right)$, the new recommendations base the result upon the delivered dose of methacholine causing a $20 \%$ fall in FEV1 (provocative dose ( $\left.\mathrm{PD}_{20}\right)$ ). This end-point allows comparable results from different devices or protocols, thus any suitable nebuliser or dosimeter may be used, so long as the delivery characteristics are known. Inhalation may be by tidal breathing using a breath-actuated or continuous nebuliser for $1 \mathrm{~min}$ (or more), or by a dosimeter with a suitable breath count. Tests requiring maximal inhalations to total lung capacity are not recommended because the bronchoprotective effect of a deep breath reduces the sensitivity of the test. 


\section{Introduction}

A task force, initially organised by the European Respiratory Society (ERS) and American Thoracic Society (ATS), co-chaired by Allan L. Coates, Bruce H. Culver, Frans H.C. de Jongh and Peter J. Sterk, was tasked with updating previous ERS publications on airway responsiveness [1] and indirect challenges [2], and an ATS guideline for methacholine and exercise challenge testing [3]. Because the time required to develop the recommended methodology for methacholine testing exceeded the timeline for ATS project support, the document was completed under ERS sponsorship, but with the participation of the full international panel. This resulting technical standard has been endorsed by the ATS. Original citations elaborated and referenced in the earlier works are not repeated in the present report. This report focuses on general considerations for bronchial challenge testing, then specifically on the performance of the methacholine challenge test (MCT). The indirect challenge tests will be addressed in a separate paper. For MCTs we describe a methodology that can be applied to a variety of delivery devices, provided that the performance characteristics of the device are known.

\section{Summary of major recommendations \\ Provocative dose}

Rather than basing the result upon a methacholine concentration (provocative concentration (PC20) causing a $20 \%$ fall in forced expiratory volume in $1 \mathrm{~s}$ (FEV1)), which requires tight specification of delivery device, we recommend basing the result upon the effective delivered dose of methacholine causing a $20 \%$ fall in FEV1 (provocative dose (PD20)). The PD20 end-point allows comparable results from different devices or protocols.

\section{Delivery devices}

Any suitable nebuliser or dosimeter may be used, but the manufacturer must provide characterisation of the device output and particle size to allow construction of a table of concentration-dose steps for the inhalation protocol.

\section{Inhalation protocol}

We recommend tidal breathing with an inhalation period of 1 min (or more) when using a breath-actuated or continuous nebuliser; when using a dosimeter, a breath count is calculated to deliver appropriate dose steps. We do not recommend a deep-breath method because the bronchoprotective effect of a deep breath reduces the sensitivity of the test.

\section{Dose steps}

We recommend a starting delivered dose of 1-3 $\mu \mathrm{g}$ with subsequent doubling or quadrupling steps. The diluted concentration required for the starting dose will be a function of the delivery device output (higher output=lower concentration) with subsequent steps using multiples of this starting concentration.

\section{General considerations for bronchial challenge testing Indications}

Bronchial challenge, or bronchoprovocation, testing is used to assess airway hyperresponsiveness (AHR), defined as an increased sensitivity and exaggerated response to nonallergenic stimuli that cause airway narrowing. While most commonly associated with asthma, AHR is also seen in other diseases associated with airway inflammation or obstruction [1,3] and is common among athletes, especially in winter sports $[4,5]$.

The degree of AHR may increase during exacerbations and decrease during treatment with antiinflammatory medications, and may be absent during asymptomatic periods. Bronchial challenge tests (BCTs), or bronchoprovocation tests, are categorised as direct or indirect challenges by the way that airway smooth muscle is stimulated to cause bronchoconstriction.

\section{Direct challenge tests}

Methacholine mimics the neurotransmitter acetylcholine to directly interact with muscarinic receptors on airway smooth muscle, resulting in contraction and airway narrowing. This occurs at a lower inhaled dose

This article has supplementary material available from erj.ersjournals.com

Received: July 302016 | Accepted after revision: Jan 152017

This report was endorsed by the European Respiratory Society Science Council and Executive Committee in February 2017, and approved by the American Thoracic Society Board of Directors in March 2017.

Conflict of interest: Disclosures can be found alongside this article at erj.ersjournals.com 
and to a greater degree in individuals with asthma or AHR than in those with normal airway responsiveness. Similar direct airway responses can be demonstrated with histamine. When the muscarinic receptors are directly stimulated, the response is felt to reflect a property of the airway smooth muscle, but airway structure and geometry also influence the response. Any reduction in airway calibre at baseline will result in a greater increase in airway resistance or airway narrowing for the same degree of muscle shortening, as will any loss of tethering forces opposing constriction [6-8].

\section{Indirect challenge tests}

Bronchoconstriction can also be elicited through exercise or other stimuli to the airways that act indirectly to cause airway narrowing. Both exercise and eucapnic hyperventilation cause airway drying and cooling, and the stimulus to bronchoconstriction is now recognised to involve the osmolar change in the airway epithelium resulting from water loss. An osmolar stimulus can also be induced by inhalation of hypertonic saline or, in a more recently developed test, by inhalation of mannitol powder. Other indirect challenge tests causing bronchoconstriction by stimulation of inflammatory cells and mediators and/or sensory nerves include adenosine monophosphate and allergen challenge. As indirect tests trigger airway narrowing through inflammatory mechanisms generated in the airways, individuals may respond differently to direct and indirect challenge tests.

\section{Report development}

This report was developed with the support of the ATS and ERS. An initial literature search was done with the assistance of University of Washington librarians. PubMed was searched from January 1, 1990 through December 15, 2009, with citations limited to human studies in English, French, German, Danish or Dutch, resulting in a total of 1811 citations (see Appendix A of the supplementary material for the full search strategy). Embase was searched through the same time period with the same language restrictions, for a total of 578 citations. The duplicate citations were removed from the total of 2389 citations, resulting in 2235 citations. An initial screen found nearly half to be off-topic or noncontributory; the remainder were divided by challenge test type. The task force was subdivided into topic-specific working groups and 308 citations were initially distributed to the methacholine group for review. As the project timeline was extended, the search was sequentially updated through 2015. The focus of review was on methodological, diagnostic or safety articles. Owing to the need to change from the former device-specific recommendation, much of the literature using that method was not applicable.

After preliminary discussions at ERS 2008 (Berlin, Germany) and ATS 2009 (San Diego, CA, USA) the project was funded and the full panel met initially in New Orleans (LA, USA) in May 2010 to plan writing strategies and allocate tasks. There was a view that insufficient data existed to make recommendations on the criteria for delivery device selection, so an in vitro study was performed with support in kind from Methapharm and Trudell Medical International (methacholine, nebulisers and blinded drug level analyses) [9]. This industry research support was disclosed to the task force, which considered it minor and not disqualifying. Subsequently, there were two human studies which formed the basis for the new recommendations [10, 11].

\section{Indications for bronchial challenge testing}

$\mathrm{BCT}$ are done to assess the presence and degree of airway responsiveness to a stimulus, measured by an index of bronchoconstriction, as a result of smooth muscle contraction along with oedema and airway closure. Apart from epidemiological or clinical research, these tests are most often done to exclude or confirm a suspected diagnosis of asthma. Asthma is most frequently diagnosed by clinical history, supported by the presence of wheezing when symptomatic and by appropriate response to therapy. Demonstration by spirometry of reversible airflow obstruction is considered confirmatory; however, spirometry is often not available at the time of symptoms and may be inconclusive when it is done, especially in those with normal or near-normal lung function values. If symptoms, spirometry or response to therapy are atypical, a BCT is appropriate and can increase or decrease the probability of asthma (further discussed in the later section on interpretation of direct BCTs). In the setting of ongoing clinical symptoms, a negative result to a test with relatively high sensitivity, such as a MCT, may be most helpful in making current asthma unlikely [1, 3]. In contrast, a positive MCT, unless at a very low dose, cannot confirm asthma. BCTs are also used in screening applicants for situations where AHR would present a high safety risk, such as commercial diving, submarine service and some occupational exposures.

In contrast to direct challenges with methacholine or histamine, indirect challenges stimulate inflammatory mediators and mechanisms involved in clinical asthma, so positive results may have a higher specificity for that diagnosis, but the test is less sensitive for a diagnosis of asthma. These may be best used when the intent is to confirm asthma, rather than to exclude it [2]. Indirect tests correlate better with airway inflammation [12] and thus may have a role in monitoring response to anti-inflammatory therapy [13]. Exercise or eucapnic hyperpnoea challenges are best indicated when history suggests these stimuli are 
involved in clinical symptoms, or when evaluating patients with suspected asthma who wish to exercise or to practise deep sea diving [14]. The use of specific inhalation challenges in the diagnosis of occupational asthma has been addressed in a recent ERS publication [15].

\title{
Contraindications
}

The contraindications to bronchial challenge testing (table 1) are conditions which may compromise the quality of the test, or which may subject the patient to increased risk or discomfort. Contraindications are identified in the pre-test interview or questionnaire and should be discussed with the physician who ordered the test or the medical director of the laboratory before proceeding. Contraindications to spirometry have recently been reviewed and updated [16].

\section{Low FEV}

Occasionally, the FEV 1 falls markedly during bronchial challenge testing and the risk of such an event may be increased when airflow obstruction is present at baseline. Reduced lung function is a relative contraindication because the overall risk of serious adverse events is small, even in asthma patients who have severe airways obstruction. The level of lung function at which bronchial challenge testing is contraindicated is controversial. Consistent with earlier recommendations, it is reasonable to not perform incremental bronchial challenge testing in patients with a pre-bronchodilator $\mathrm{FEV}_{1}<60 \%$ predicted or $1.5 \mathrm{~L}$ in adults, or with an FEV $1<75 \%$ predicted for tests with a single high stimulus such as exercise [3]. The same percentage predicted values can be used as a guideline in children. In actual practice, a low FEV1 may cause more problems with interpretation than with safety because reduced airway calibre at baseline can itself cause an exaggerated response [17].

\section{Spirometry quality}

An acceptable quality BCT depends on the patient's ability to perform acceptable spirometric manoeuvres [18].

\section{Cardiovascular problems}

Bronchoconstriction may precipitate cardiovascular events in patients with uncontrolled hypertension (systolic $>200 \mathrm{mmHg}$, diastolic $>100 \mathrm{mmHg}$ ) or recent myocardial infarction or stroke as well as arterial hypoxaemia due to ventilation/perfusion mismatching [3].

\section{Eye surgery}

Recent eye surgery or any condition where raised intracranial pressure (caused by forceful exhalation) would be harmful is a contraindication.

\section{Technician/respiratory scientist training and qualifications}

The pulmonary laboratory director is responsible for evaluating and/or verifying the training and qualification of the person(s) who perform the test and assuring conformance with any jurisdictional competency standards. Minimum qualifications are summarised in table 2. It is estimated that apart from adequate background knowledge, $\sim 4$ days of hands-on training and at least 20 supervised tests are required for a new technician/respiratory scientist to become proficient in methacholine challenge testing [19]. A similar requirement is likely for other BCTs. The testing, training and safety recommendations are designed to ensure good quality data, and patient and technician/respiratory scientist safety.

\section{TABLE 1 Contraindications for bronchial challenge testing}

\author{
Airflow limitation \\ FEV $1<60 \%$ predicted (adults or children) or $1.5 \mathrm{~L}$ (adults) \\ FEV $1<75 \%$ predicted (adults or children) for exercise or eucapnic voluntary hyperpnoea challenge \\ Spirometry quality \\ Inability to perform acceptable and repeatable spirometry manoeuvres throughout the test procedure \\ Cardiovascular problems \\ Myocardial infarction or stroke in last 3 months \\ Uncontrolled hypertension \\ Known aortic aneurysm \\ Recent eye surgery or intracranial pressure elevation risk \\ General \\ Inability to perform any of the testing manoeuvres, such as inhaling the challenge agent consistently \\ or difficulty with exercise on treadmill or bike; most commonly in young children or elderly patients
}

FEV1: forced expiratory volume in $1 \mathrm{~s}$. 
TABLE 2 Qualifications to perform bronchial challenge tests

The technician/respiratory scientist should:

1) Have background knowledge of respiratory diseases, be familiar with this guideline and knowledgeable about specific test procedures

2) Be capable of managing the equipment including set-up, calibration checks, verification of proper function, maintenance, hygiene and cleaning

3) Be proficient at spirometry

4) Know the contraindications to bronchial challenge testing

5) Be familiar with safety and emergency procedures

6) Know when to stop further testing

7) Be proficient with the administration of inhaled bronchodilators and evaluation of the response to them

Precautions for patient safety

The medical director of the laboratory, another physician or another person appropriately trained to treat acute bronchoconstriction, including appropriate use of resuscitation equipment, must be close enough to respond quickly to an emergency. Patients should not be left unattended once a BCT has begun and should not be sent home unless their lung function at post-testing has recovered to within $10 \%$ of baseline values. A spontaneous recovery post-methacholine testing usually occurs within 45-60 min [20]; however, patients are usually given a bronchodilator to relieve challenge-induced bronchoconstriction.

Medications to treat severe bronchoconstriction must be present in the testing area. They include epinephrine for subcutaneous injection and albuterol (salbutamol) in metered-dose inhalers with an appropriate valved holding chamber, dry powder inhalers or pre-mixed solutions for inhalation in a small-volume nebuliser. Oxygen must be available. A stethoscope, sphygmomanometer and pulse oximeter should be available.

\section{Methacholine challenge testing}

Methacholine is a synthetic derivative of the neurotransmitter acetylcholine and directly stimulates muscarinic (M3) receptors on airway smooth muscle when inhaled. Methacholine is metabolised by acetylcholinesterase, but more slowly than acetylcholine; its effects can be partially blocked by anticholinergic agents such as ipratropium bromide (table 3).

\section{Indications and specific contraindications}

The primary indication for a MCT is to help determine if current respiratory symptoms may be due to asthma or to make that diagnosis much less likely. See general contraindications for bronchial challenge testing discussed earlier in this report; in addition there are relative contraindications specific to methacholine challenge testing including:

1) Pregnancy and nursing mothers. No animal reproductive studies have been conducted and it is not known whether methacholine chloride is associated with fetal abnormalities if administered to a pregnant patient or if it effects reproductive capacity. It is also not known whether methacholine chloride when inhaled is excreted in breast milk.

2) Current use of cholinesterase inhibitor medication (e.g. for myasthenia gravis).

TABLE 3 Medications which may decrease airway hyperresponsiveness and withholding time

Medication

Short-acting $\beta$-agonists in conventional

inhaled doses (e.g. albuterol $200 \mu \mathrm{g}$ )

Long-acting $\beta$-agonists (e.g. salmeterol)

Ultra-long-acting $\beta$-agonists le.g. indacaterol, vilanterol, olodaterol)

Ipratropium (Atrovent $\mathbf{4 0} \mu \mathrm{g}$ )

Long-acting anti-muscarinic agents

Oral theophylline
Minimum time interval

from last dose to MCT $h$

MCT: methacholine challenge test.
6

36

48

12

$\geqslant 168$

$12-24$

Reference(s)

$[21,22]$

$[23,24]$

$[29,30]$

[3] 
Safety

Inhaled methacholine causes bronchoconstriction. The safety of both patients and technicians/respiratory scientists should be considered in the design of the test room and the testing procedures. Vials must be clearly labelled, and care should be taken to never escalate the dose more rapidly than the protocol dictates and to avoid unintentional delivery of a high concentration or dose of methacholine. When there is $<20 \%$ drop in FEV1, the next dose step can be administered with little risk of severe bronchoconstriction.

Thousands of MCTs have been performed by laboratories without serious side-effects [3]. Transient, generally mild, symptoms including wheezing, cough, dyspnoea and chest tightness are common in patients with AHR, although many experience no symptoms. Delayed or prolonged responses to methacholine are rare [31]. Although we are not aware of any deaths associated with methacholine challenge testing, the potential for severe bronchoconstriction is present and prudent measures to minimise risk should be in place. (See patient safety precautions discussed earlier in this report.)

\section{Precautions for technician/respiratory scientist safety during methacholine challenge testing}

Measures should be taken to minimise technician exposure to methacholine aerosol, especially for those with asthma or a positive methacholine challenge [3]. The testing room must have adequate ventilation to provide at least two complete exchanges of air per hour. Other, optional methods to reduce methacholine exposures include using low resistance exhalation filters, a laboratory fume hood, supplemental local exhaust ventilation and/or a HEPA room air cleaner. The use of a mouthpiece so that exhaled methacholine can be directed onto a filter is preferable to the use of a face mask, where environmental contamination is inevitable (and pulmonary deposition will be less than with a mouthpiece [32]). Furthermore, if the subject comes off the nebuliser for any reason (e.g. to cough), any aerosol that continues to be produced directly enters the room. Use of a breath-actuated nebuliser will minimise environmental methacholine exposure since aerosol is produced only during inspiration. Such nebulisers produce an aerosol only once a certain inspiratory flow has been reached or, alternatively, a pulse of aerosol once inspiration is sensed. However, some environmental loss is always present unless a filter is placed on the expiratory limb [9]. Technicians/ respiratory scientists may also want to stand well away from the patient when methacholine is being nebulised, which can be a challenge if they are required to assist a coughing patient.

\section{Choice and preparation of methacholine}

Chemically, methacholine chloride (the active ingredient) is 2-(acetyloxy)- $N, N, N$-trimethylpropan1 -aminium chloride. It is available as a dry crystalline powder with an empirical formula of $\mathrm{C}_{8} \mathrm{H}_{18} \mathrm{ClNO}_{2}$ and a calculated molecular weight of 195.69. Where available, it is the agent of choice for direct bronchial challenge testing. A form of methacholine approved by the US Food and Drug Administration (Provocholine) is packaged in sealed 100-mg vials, and is available in North America and increasingly elsewhere. Although industrial sources of methacholine appear to work as well as Provocholine [33], these are not approved for human use and are not recommended by the task force. Where methacholine is formulated locally, the laboratory must assure that Good Manufacturing Practices are met for quality, purity and consistency. Sealed pre-packaged vials have a shelf-life of 2-3 years at ambient temperature. Methacholine solutions should be mixed by a pharmacist or other qualified, well-trained individual using sterile technique and following the manufacturer's instructions (tables 4 and 5). There is no evidence that adding a preservative such as phenol to sterile saline diluent is necessary [34] nor is there evidence that use of phenol adversely affects MCT. Both diluents are widely used. The potential benefit of adding phenol is to reduce the possibility of bacterial contamination. The $\mathrm{pH}$ of methacholine in normal saline solution is weakly to moderately acidic depending upon the concentration of methacholine. Buffered solutions are less stable and should not be used as the diluent $[3,34]$. Solutions of methacholine should be warmed to room temperature before testing begins [3].

\section{Preparation when scheduling}

When MCTs are scheduled, patients should be given a list of medications to avoid prior to the test, including alcohol $4 \mathrm{~h}$ and smoking $1 \mathrm{~h}$ before the test [35]. Table 3 lists medications that can decrease airway responsiveness and the time period for which each should be witheld prior to the test. Asthma medications other than bronchodilators may be continued when the purpose of the test is to monitor response to therapy. Cromones, inhaled corticosteroids and leukotriene modifiers have little or no effect in single dose [36-39], and do not need to be withheld unless the intent is to offload an anti-inflammatory effect; duration of effect after regular use is uncertain but a withhold time of 4-8 weeks [40] is reasonable. Normal dietary servings of caffeine and caffeine-related products (e.g. chocolate) have no effect of clinical significance [41], although theophylline does have an effect [42] and should be withheld [3] (table 3). Influenza vaccination, the menstrual cycle and oral contraceptives do not significantly affect airway responsiveness [43-45]. Antihistamines do not effect methacholine response [46, 47]. 
TABLE 4 Example of doses using the English Wright nebuliser for 2 min

\begin{tabular}{|c|c|c|c|}
\hline \multicolumn{2}{|c|}{ Doubling increments } & \multicolumn{2}{|c|}{ Quadrupling increments } \\
\hline Concentration $\mathrm{mg} \cdot \mathrm{mL}^{-1}$ & Dose $\mu \mathrm{g}$ & Concentration $\mathrm{mg} \cdot \mathrm{mL}^{-1}$ & Dose $\mu \mathrm{g}$ \\
\hline 0.0625 & 1.425 & 0.0625 & 1.425 \\
\hline 0.125 & 2.969 & & \\
\hline 0.25 & 5.938 & 0.25 & 5.938 \\
\hline 0.5 & 11.875 & & \\
\hline 1 & 23.75 & 1 & 23.75 \\
\hline 2 & 47.5 & & \\
\hline 4 & 95 & 4 & 95 \\
\hline 8 & 190 & & \\
\hline 16 & 380 & 16 & 380 \\
\hline
\end{tabular}

Shown are the incremental doses at specific concentrations for both doubling and quadrupling increments.

There are a number of factors that will increase airway responsiveness, although the duration and magnitude of effect is unknown. AHR caused by exposure to environmental allergen can last for weeks and occupational sensitisers for months. Air pollutants and chemical irritants can have effects for days to months, while the effect of cigarette smoking is not well established [3].

\section{Preparation before testing}

1) Administer a pre-test questionnaire (see Appendix B of the supplementary material for an example). The pre-test evaluation will alert the technician/respiratory scientist to important issues including: a) the presence of contraindications to proceeding with the test; b) conditions or exposures, such as a recent viral infection, which could temporarily increase airway responsiveness and cause a false-positive response; and c) the presence of medications that may alter airway responsiveness (table 3).

2) Explain the test to the patient. Patients should be told that they may experience some minor symptoms, such as cough or chest tightness, but that most patients have no evident symptoms. They should be warned that severe symptoms may occasionally occur. Care should be taken to assure that the test description does not bias the result. For example, avoid stating that the test induces an asthma attack.

TABLE 5 Dilution schedules for preparing methacholine solutions

\begin{tabular}{|c|c|c|c|}
\hline Label strength & Take & Add $\mathrm{NaCl}(0.9 \%)$ & Obtain dilution \\
\hline \multicolumn{4}{|c|}{ Example of a dilution schedule for quadrupling concentrations } \\
\hline \multirow[t]{6}{*}{$100 \mathrm{mg}$} & $100 \mathrm{mg}$ & $6.25 \mathrm{~mL}$ & A: $16 \mathrm{mg} \cdot \mathrm{mL}^{-1}$ \\
\hline & $3 \mathrm{~mL}$ of dilution $\mathrm{A}$ & $9 \mathrm{~mL}$ & $\mathrm{~B}: 4 \mathrm{mg} \cdot \mathrm{mL}^{-1}$ \\
\hline & $3 \mathrm{~mL}$ of dilution $\mathrm{B}$ & $9 \mathrm{~mL}$ & $\mathrm{C}: 1 \mathrm{mg} \cdot \mathrm{mL}^{-1}$ \\
\hline & $3 \mathrm{~mL}$ of dilution $\mathrm{C}$ & $9 \mathrm{~mL}$ & $\mathrm{D}: 0.25 \mathrm{mg} \cdot \mathrm{mL}^{-1}$ \\
\hline & $3 \mathrm{~mL}$ of dilution $\mathrm{D}$ & $9 \mathrm{~mL}$ & $\mathrm{E}: 0.0625 \mathrm{mg} \cdot \mathrm{mL}^{-1}$ \\
\hline & $3 \mathrm{~mL}$ of dilution $\mathrm{E}$ & $9 \mathrm{~mL}$ & $\mathrm{~F}: 0.015625 \mathrm{mg} \cdot \mathrm{mL}^{-1}$ \\
\hline \multicolumn{4}{|c|}{ Example of a dilution schedule for doubling doses } \\
\hline \multirow{10}{*}{$100 \mathrm{mg}$} & $100 \mathrm{mg}$ & $6.25 \mathrm{~mL}$ & A: $16 \mathrm{mg} \cdot \mathrm{mL}^{-1}$ \\
\hline & $3 \mathrm{~mL}$ of dilution $\mathrm{A}$ & $3 \mathrm{~mL}$ & $\mathrm{~B}: 8 \mathrm{mg} \cdot \mathrm{mL}^{-1}$ \\
\hline & $3 \mathrm{~mL}$ of dilution $\mathrm{B}$ & $3 \mathrm{~mL}$ & $\mathrm{C}: 4 \mathrm{mg} \cdot \mathrm{mL}^{-1}$ \\
\hline & $3 \mathrm{~mL}$ of dilution $\mathrm{C}$ & $3 \mathrm{~mL}$ & $\mathrm{D}: 2 \mathrm{mg} \cdot \mathrm{mL}^{-1}$ \\
\hline & $3 \mathrm{~mL}$ of dilution $\mathrm{D}$ & $3 \mathrm{~mL}$ & $\mathrm{E}: 1 \mathrm{mg} \cdot \mathrm{mL}^{-1}$ \\
\hline & $3 \mathrm{~mL}$ of dilution $\mathrm{E}$ & $3 \mathrm{~mL}$ & $\mathrm{~F}: 0.5 \mathrm{mg} \cdot \mathrm{mL}^{-1}$ \\
\hline & $3 \mathrm{~mL}$ of dilution $\mathrm{F}$ & $3 \mathrm{~mL}$ & $\mathrm{G}: 0.25 \mathrm{mg} \cdot \mathrm{mL}^{-1}$ \\
\hline & $3 \mathrm{~mL}$ of dilution $\mathrm{G}$ & $3 \mathrm{~mL}$ & $\mathrm{H}: 0.125 \mathrm{mg} \cdot \mathrm{mL}^{-1}$ \\
\hline & $3 \mathrm{~mL}$ of dilution $\mathrm{H}$ & $3 \mathrm{~mL}$ & $\mathrm{I}: 0.0625 \mathrm{mg} \cdot \mathrm{mL}^{-1}$ \\
\hline & $3 \mathrm{~mL}$ of dilution I & $3 \mathrm{~mL}$ & $\mathrm{~J}: 0.03125 \mathrm{mg} \cdot \mathrm{mL}^{-1}$ \\
\hline \multicolumn{4}{|c|}{$\begin{array}{l}\text { Using a } 100-\mathrm{mg} \text { vial of methacholine and } \mathrm{NaCl}(0.9 \%) \text { for diluent, the table shows the range of } \\
\text { concentrations available to produce appropriate dose steps using examples of dilutions with quadrupling and } \\
\text { doubling increases. If necessary, alternative concentrations can be produced from a different initial dilution } \\
\text { step. For example, adding } 5 \mathrm{~mL} \text { of diluent to } 100 \mathrm{mg} \text { methacholine would produce dilution } \mathrm{A} \text { of } 20 \mathrm{mg} \cdot \mathrm{mL}^{-1} \\
\text { and adding } 8.3 \mathrm{~mL} \text { of diluent to } 100 \mathrm{mg} \text { methacholine would produce dilution } \mathrm{A} \text { of } 12 \mathrm{mg} \cdot \mathrm{mL}^{-1} \text {. }\end{array}$} \\
\hline
\end{tabular}


3) Ask the patient if they would like to urinate before the test because the forced expiration could precipitate stress incontinence, especially in older women.

4) Obtain informed consent for testing if required by the hospital or clinic (see Appendix $\mathrm{C}$ of the supplementary material for an example of an informed consent document).

5) A brief pre-test physical examination of the chest and lungs may be useful but is not required.

\section{During testing}

1) Patients must be able to understand the procedure and perform reliable spirometric manoeuvres.

2) Patients should be seated comfortably throughout the test on a stable chair with elbow rests and no wheels.

\section{Provocative dose versus provocative concentration}

Methacholine acts by binding to smooth muscle receptors, so the strength of the stimulus is directly related to the number of molecules $(\mu \mathrm{mol})$ of methacholine delivered to the lower airways (i.e. delivered dose). The delivered methacholine dose at any level of a challenge protocol is related to the concentration of the solution administered, but also to the output rate of the administration device, time of aerosol inhalation and particle size distribution. A study showing that the results of a 2-min tidal breathing protocol were matched by $30 \mathrm{~s}$ of tidal breathing at a four-fold higher concentration demonstrates that the primary stimulus is dose rather than concentration [48]. In the 1999 ATS guideline, methacholine concentration was taken as a surrogate for delivered dose and results expressed as the PC20 [3]. The methacholine concentration is readily available from the prepared solution, but the delivered dose is dependent upon the nebuliser characteristics and inhalation protocol, which requires the specification of an output rate and limited the choice of devices. Substituting devices with different aerosol production characteristics would be expected to deliver a different stimulating dose at the same solution concentration. For example, in both adults and children when comparing the English Wright nebuliser with 2 min of tidal breathing to a high-output breath-actuated nebuliser, even with the breathing time shortened to $20 \mathrm{~s}$, the latter delivered a greater dose at each concentration step, resulting in a fall of $20 \%$ in $\mathrm{FEV}_{1}$ at approximately one less doubling concentration than the former $[10,11]$. As the devices most commonly used for the two protocols recommended in 1999 are now obsolete and difficult to obtain, many laboratories have turned to alternate nebulisers that may not be fully characterised.

Current technology has made it easier to measure nebuliser output and particle size distribution, making it feasible to calculate a delivered dose for any combination of device and inhalation protocol. While some laboratories have been reporting a provocative dose, these doses are typically calculated from nebuliser output by weight, which includes evaporative loss, and delivery to the mouth rather than the lower airways. An example of the calculation of delivered dose as recommended is shown in Appendix D of the supplementary material. There is now evidence that the methacholine dose, expressed as PD20, allows more consistent correlation of results than does PC20 when comparing responses done by different protocols $[10,49,50]$. As methacholine challenge protocols use doubling or quadrupling increases between steps, the cumulative delivered dose is dominated by the last one or two steps. The effective delivered dose at any step is influenced by prior steps, but will be less than the total cumulative delivered dose because methacholine is slowly metabolised [51]. For this reason, consistency of timing between steps and from dosing to spirometry remains important. The PD20 is the dose of methacholine that causes a $20 \%$ fall in FEV 1 and is calculated in the same way as the PC20. These calculations are outlined in Appendix E of the supplementary material. The true PD20 will lie between the final dose and the total cumulative dose (or more commonly the values interpolated between the two final steps). Reanalysis of the results from DELL et al. [10] and EL-Gammal et al. [11] showed that using a PD20 calculated from final doses was equally effective as that calculated from cumulative doses in achieving comparable results from different delivery devices [52]. For simplicity, we recommend calculating PD20 as the delivered dose interpolated between the dose steps before and after a $20 \%$ fall in FEV1, without consideration of prior cumulative effect.

\section{Delivery methods and dosing regimens}

Of the many different MCT delivery methods and dosing protocols that have been used, the 1999 ATS guideline recommended the 2-min tidal breathing method and the five-breath dosimeter method, each with a specified delivery system [3]. Although calculations estimated that the dose of methacholine delivered at each step would be twice as high with the tidal breathing method, it was expected that deep breaths with a $5 \mathrm{~s}$ breathhold at total lung capacity (TLC) would allow better distribution and retention of the aerosol, and early studies did suggest that the two delivery methods gave similar results [3]. More recent studies have shown small differences between the methods when the PC20 was low in more severe asthmatic subjects, but the methods are not as comparable in subjects with less AHR [53, 54]. A subject 
considered to have mild AHR by the 2-min tidal breathing method might be considered normal by the dosimeter method. This false-negative rate was $25 \%$ of all tests and $50 \%$ of those with mild/moderate AHR in one series [55]. The difference may be attributed to the bronchodilating or bronchoprotective effect of a maximal inspiratory manoeuvre with a breathhold at TLC. This effect is seen in normal subjects and mild asthmatic subjects, but is lost with more severe disease [56-58]. The performance of the test at low levels of AHR is particularly important because one of the primary values of the MCT is its negative predictive value to make a diagnosis of asthma unlikely. For these reasons, methods requiring deep inhalations to TLC during aerosol delivery are no longer recommended. While the five-deep-breaths method is not recommended, a dosimeter device with a breath count may be used for dose delivery with tidal or submaximal inhalations, which do not elicit the same bronchoprotective effect; however, controlling the latter may be difficult [59].

\section{Aerosol delivery systems}

There are a number of factors guiding aerosol delivery. Most systems use a high-pressure source of gas to which the liquid is exposed and fragmented into droplets (i.e. jet nebuliser). The majority of the droplets are too large to deposit in the lung so a baffle or series of baffles is placed in the device. As the air containing the droplets is forced around the baffle, only the smaller droplets will remain in suspension, with the larger droplets striking the baffle and falling back into the nebuliser reservoir. In general, the higher the nebulising airflow, the greater the output and the smaller the particle size distribution of the generated aerosol. However, since the volume of a droplet is proportional to the third power of the radius, the tiny droplets contain very little methacholine. Thus, the output of nebulisers that produce aerosols of very tiny particles is generally low. However, particles $>5 \mu \mathrm{m}$, when inhaled, are likely to deposit in the posterior pharynx as opposed to the pulmonary airways [60]. Hence, many nebulisers are designed to have as high an output as possible but with a particle size distribution $\leqslant 5 \mu \mathrm{m}$. Changing nebuliser flow and the humidity of the driving flow (compressor versus dry hospital air) can affect both output and particle size distribution, but especially the latter [61, 62].

The two delivery systems recommended in the 1999 ATS guideline were the English Wright nebuliser for the 2-min tidal breathing protocol and the DeVilbiss 646 nebuliser for the five-breath dosimeter method [3]. Both devices are now considered obsolete by modern aerosol standards and the English Wright nebuliser is difficult to acquire. In order to accommodate different devices available now and in the future, we recommend the calculation of stepwise delivered doses starting at $1-3 \mu \mathrm{g}$ followed by either doubling or quadrupling steps [3]. This calculation requires knowledge of the device output per minute, the particle size distribution to estimate the fraction delivered to the lower airways, time of tidal breathing and the ratio of inspiratory time to total breathing time (TI/TTOT). For a breath-actuated dosimeter device, the calculation requires particle size distribution, output per breath and breath number. Previously, output calibration was done gravimetrically which, when using the English Wright, was not ideal because most of the change in weight was due to evaporative losses [3]. Even though the amount of evaporative loss is much less in newer jet nebulisers or high-efficiency devices such as the vibrating mesh nebulisers, direct measurement of both drug output and particle size distribution for each type of nebuliser is necessary in order to accurately estimate the amount of drug delivered to the lower airways. Such a measurement of drug output can be measured by collection on a filter and should be provided by the device manufacture.

\section{Dose delivery by the English Wright nebuliser}

This device required calibration by adjusting the flow (dry gas source) to produce an output within $10 \%$ of $0.13 \mathrm{~mL} \cdot \mathrm{min}^{-1}$ (or g. $\mathrm{min}^{-1}$ ) (measured gravimetrically) with a particle size that is generally considered to be $<2 \mu \mathrm{m}$. Virtually all of an aerosol of this size is assumed to be inhaled below the vocal cords, although some of the inhaled aerosol may be exhaled before it has time to deposit in the lungs. In vitro modelling using a simulated adult respiratory pattern $(15 \times 750 \mathrm{~mL}$, with TI/TTOT=0.4) showed that 2 min of tidal breathing resulted in deposition on a filter at the mouthpiece of $0.38 \mathrm{mg}$ for a $16 \mathrm{mg} \cdot \mathrm{mL}^{-1}$ concentration and $0.08 \mathrm{mg}$ for a $4 \mathrm{mg} \cdot \mathrm{mL}^{-1}$ concentration [9]. These values are much less than one would calculate from output $\times$ concentration because most of the weight loss is from evaporation rather than the output of methacholine [63].

\section{Tidal breathing method}

Time

The prior recommendation of tidal breathing for $2 \mathrm{~min}$ was influenced by data showing better reproducibility with this time compared to $30 \mathrm{~s}$ of tidal breathing [64]. Using newer devices with higher rates of dose delivery than the English Wright nebuliser will require shorter nebulisation time or lower initial concentration or both. For example, in vitro data shows that one modern nebuliser would deliver the same amount of methacholine in $12 \mathrm{~s}$ as the English Wright did in $2 \mathrm{~min}$, i.e. a 10-fold increase [9]. 
In vivo data exists for both 20 and $30 \mathrm{~s}$ using a breath-activated nebuliser [10, 11]. To reduce the variability of dose delivery based on the breathing pattern, the task force recommends a breathing time of at least $1 \mathrm{~min}$. While a 2 -min breathing time might further improve reproducibility, this would require additional reduction in initial concentration for high-output devices and the linearity of effect at such low concentrations has not been established. Modified protocols including 1-min breathing times have been published, but there is a need for more in vivo data using modern nebulising systems [65].

\section{Dosing}

To achieve appropriate dose increments, the stepwise concentrations must be chosen based on delivery device performance characteristics. As the end-point is based on the calculated dose, there is no necessity to mimic the steps of the English Wright protocol, but table 4 could be used as a guide. The manufacturer of a nebuliser, dosimeter or integrated device intended for methacholine challenge testing must provide a schedule of concentrations and tidal breathing times or breath number that will achieve delivery of appropriate methacholine doses, or must provide sufficient characterisation of aerosol output and particle size to allow construction of an appropriate dosing protocol.

Based on the experience with the 2-min English Wright protocol, a starting dose of 1-3 $\mu \mathrm{g}$ is considered safe in the routine testing environment where subjects typically have normal or near-normal spirometry and no significant bronchodilator response. In a research setting, or for those for whom a marked response may be anticipated, or for young children, limiting the starting dose to $\sim 1 \mu \mathrm{g}$ would be an option. As the dose delivered to the lungs will vary depending on the nebuliser used and the inhalation protocol, the concentration available from the standard dilution steps (table 5) needed to achieve an appropriate starting dose will have to be calculated. Subsequent doubling or quadrupling of this initial concentration will yield a stepwise dosing protocol which is followed until a drop of $20 \%$ in the FEV 1 is seen or a delivered dose step of $\geqslant 400 \mu \mathrm{g}$ is reached. (For a quadrupling protocol, it would be prudent to make any step above $400 \mu \mathrm{g}$ a doubling, so that no dose $>800 \mu \mathrm{g}$ is delivered.)

\section{Procedure steps}

Since there is a cumulative effect of methacholine, which diminishes over time, standardising the time of the start of delivery with the time of spirometry is absolutely essential for consistency of test results. The procedure steps are enumerated below and outlined in figure 1.

1) Prepare the predetermined methacholine concentrations in sterile vials, place them in a holder and store them in a refrigerator. Assure spirometer is working properly and that calibration checks have been performed.

2) Remove the vials from the refrigerator $\sim 30 \mathrm{~min}$ before testing so the mixtures warm to room temperature before use. Insert an appropriate volume of the diluent (e.g. $3 \mathrm{~mL}$ ) into the nebuliser, using a sterile syringe.

3) Assure correct patient preparation (described earlier) and perform pre-challenge spirometry to assure the patient can perform acceptable and repeatable spirometry, and to determine if challenge is contraindicated because of airflow limitation at baseline.

4) Aerosolise the diluent using the chosen (pre-calibrated) nebuliser that will also be used for the methacholine solutions. The diluent step is recommended, particularly if this is the first challenge test for the patient, and to ensure there is no excessive AHR (see under Step 7 for post-diluent FEV1). Apply a nose clip and instruct the patient to relax and breathe quietly (tidal breathing) for the appropriate time for the specific nebuliser. The nebuliser must be placed upright in a holder, or held by the patient, with the mouthpiece in his/her mouth.

5) Watch the patient to ensure that he/she is breathing comfortably and quietly, and not tipping the nebuliser. After the appropriate time for that nebuliser, turn off the flowmeter and take the nebuliser from the patient.

6) Perform post-diluent spirometry at 30 and $90 \mathrm{~s}$ after the nebulisation is completed. Obtain an acceptable quality FEV1 and forced vital capacity (FVC). This may require repeated attempts. Calculate a target $\mathrm{FEV}_{1}$ that indicates a $20 \%$ fall in $\mathrm{FEV}_{1}$ (baseline $\mathrm{FEV} 1 \times 0.8$ ) using the post-diluent data.

7) The diluent should not cause significant change from the pre-challenge testing spirometry. If the $\mathrm{FEV}_{1}$ has increased or decreased by $<10 \%$ from the pre-challenge $\mathrm{FEV}_{1}$, proceed to administer the first dose of methacholine in the same manner the diluent was administered (Steps 4 and 5). If the FEV1 has increased or decreased by 10-20\% after diluent, repeat diluent step (Step 4). In some cases when there has been a large change in FEV1 after diluent, the patient may be considered to be too unstable to continue the challenge and should be rescheduled. If there has been a $\geqslant 20 \%$ fall in FEV1 after diluent, the challenge should be cancelled.

8) Aerosolise the methacholine using the same nebuliser used for diluent. Perform post-methacholine spirometry at 30 and $90 \mathrm{~s}$ after the nebulisation is completed. Obtain an acceptable quality FEV1 at each 
time point. Perform no more than three or four manoeuvres after each dose. Obtaining a full FVC is not required for response measurements. It should generally take no more than $3 \mathrm{~min}$ to perform these manoeuvres. In order to keep the cumulative effect of methacholine relatively constant, the time interval between the commencement of two serial concentrations should be kept constant at $5 \mathrm{~min}$.

9) At each dose, report the highest FEV1 from the acceptable manoeuvres.

10) If FEV 1 falls $<20 \%$ from the post-diluent FEV1, empty the nebuliser, add the appropriate volume of the next highest concentration and repeat Step 8.

11) If FEV 1 falls $>20 \%$ from the post-diluent FEV 1 (or the highest dose step has been administered), give no further methacholine, note signs and symptoms, administer a rapidly acting inhaled bronchodilator, wait 5-10 min, and repeat the spirometry. If vocal cord dysfunction is suspected and the patient's symptoms allow it, full inspiratory and expiratory flow-volume loops may be performed prior to giving the bronchodilator.

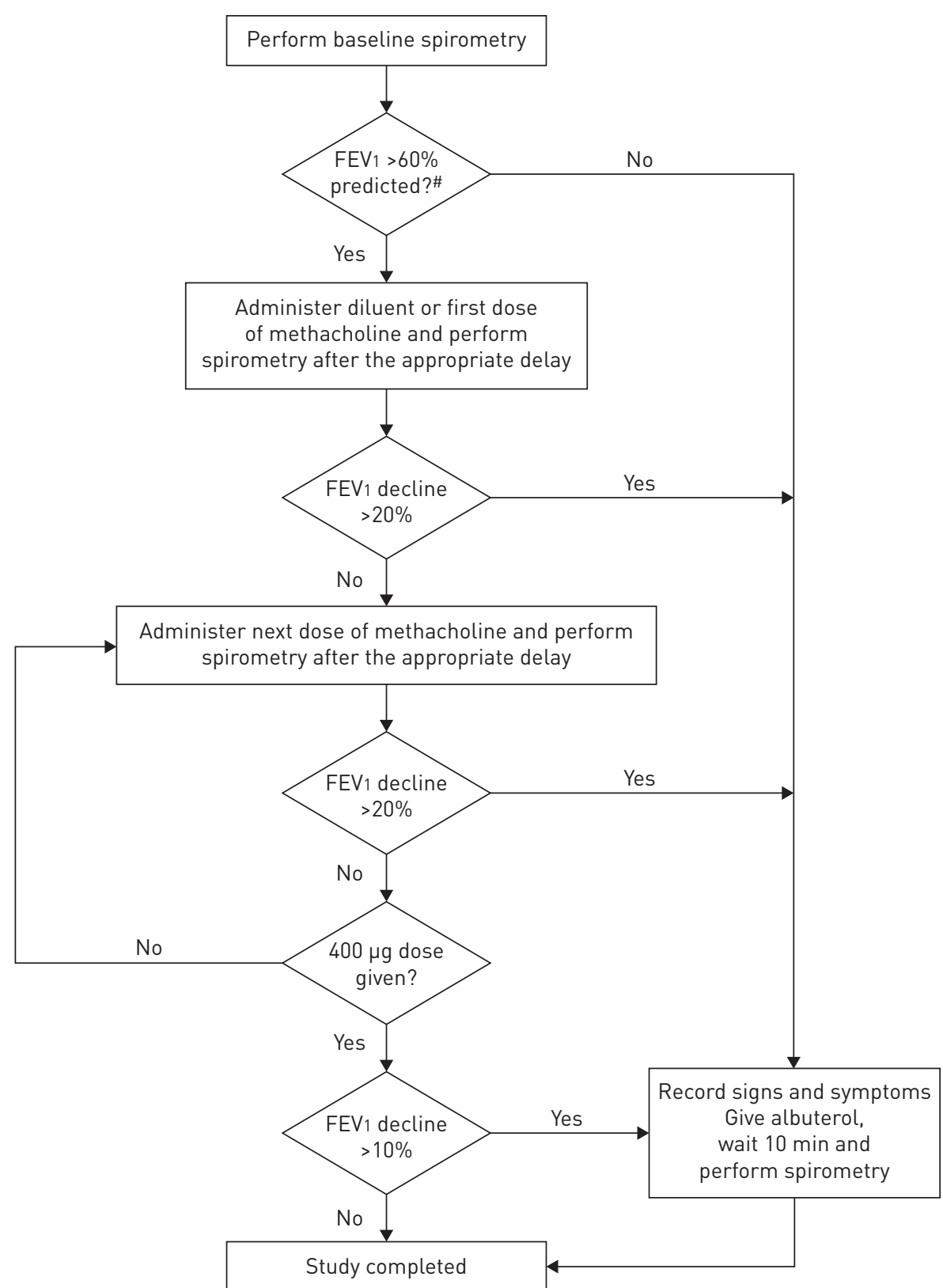

FIGURE 1 Testing sequence flow chart. FEV1: forced expiratory volume in $1 \mathrm{~s} .{ }^{*}$ : FEV $1<1.5 \mathrm{~L}$ in adults is an additional contraindication. Reproduced and modified from [3] with permission. 


\section{Discussion and rationale}

\section{Dosing regimens}

Differing dosing protocols have been used by different investigators and laboratories. Doubling concentrations are widely recommended for research protocols and are mathematically attractive, but the small steps increase the time needed for a test. Fewer concentration steps have been used by many investigators in order to save time [66-70], without any apparent increase in risk of severe bronchoconstriction. We recommend quadrupling increments for clinical testing, but if methacholine challenge testing is used to determine changes in airway reactivity following therapy in patients known to have asthma, using doubling doses will give more precise PD20 values.

\section{Use of a diluent step}

Most current protocols start with a diluent step and we support its use. An advantage of starting with a diluent is that it gives patients an opportunity to learn the technique of inhaling from the nebuliser and practise in performing spirometry. In addition, most reference data used for interpretation are based on studies that used a diluent step, so this provides a better link to interpretative data. However, the starting concentration of methacholine was chosen so that only the most hyperresponsive patients will respond and the use of a diluent control does not improve the safety of the test. The end-point is not affected by starting with a diluent. The addition of a diluent control adds $4-5 \mathrm{~min}$ to each test. While only $1 \%$ of patients tested using a diluent (control) respond to the diluent with $\mathrm{a} \geqslant 20 \%$ fall in $\mathrm{FEV} 1, \mathrm{a} \geqslant 10 \%$ change occurred $5.8 \%$ of the time [71]. Variability in lung function during the diluent step may decrease the accuracy of the measurement of AHR. The clinical meaning of a positive response to the diluent is unknown; some patients may be hyperresponsive to the diluent (saline) or may be experiencing FVC manoeuvre-induced bronchoconstriction.

\section{Nebulisers and dosimeters}

Prior guidelines included considerable detail on calibration of the devices used. Modern nebulisers have performance characteristics that are reproducible, and must be measured and reported by the manufacturer. Ideally this will include using a breath simulator and collecting the aerosol on a filter at the "mouth" of the simulator plus the determination of particle size. The particle size distribution can be used to calculate the respirable fraction defined as the fraction of the mass of the inhaled aerosol that will deposit below the vocal cords. This can be considered as the fraction of the mass carried in droplets $\leqslant 5 \mu \mathrm{m}$; such methods are well described in the literature [72-74]. Methacholine is difficult to assay; however, a reasonable substitute is an aqueous solution of albuterol, which has a double bond that makes it relatively easy to assay by UV spectrophotometry $[72,75]$. The output of the device per minute can be expressed as a percentage of the initial amount put in the nebuliser which can be converted to $\mu g \cdot \mathrm{min}^{-1}$, based on the methacholine concentration of interest. Particle size can be determined by either laser diffraction [76, 77] or inertial impaction techniques [76] providing care is taken to insure that the impaction device is at the same temperature as the aerosol leaving the nebuliser [78, 79]. It is imperative that the details of the particle size measurement are given by the manufacturer.

\section{Spirometry and other end-point measures}

Spirometry

Change in FEV1 from post-diluent baseline value is the primary outcome measure for MCT. Spirometry should meet current ATS/ERS guidelines [18]. Special care should be taken to obtain high-quality baseline (i.e. post-diluent) FEV1 measurements since unacceptable manoeuvres may result in false-positive or false-negative results. The quality of the volume-time and flow-volume curves should be examined after each manoeuvre. Full FVC efforts lasting at least $6 \mathrm{~s}$ should be performed at baseline, i.e. pre-challenge and post-diluent, preferably a full flow-volume loop with inspiratory flow may be performed at these points. If FEV1 is the only outcome being measured, the expiratory manoeuvre can be shortened to $\sim 2 \mathrm{~s}$ for post-methacholine spirometry, but it is important to be sure that the inspiratory manoeuvre is rapid with a pause of $<1 \mathrm{~s}$ at peak inspiration [18]. If a shortened expiratory time is used, technicians/respiratory scientists should comment that an abbreviated expiratory time was used and should take care that the inspiration is complete since incomplete inhalations will result in a false reduction in FEV1. If other spirometric outcome variables are used or if vocal cord dysfunction is suspected, full FVC manoeuvres including inspiration should be performed throughout the test. The highest FEV1 value from acceptable tests is selected for the outcome variable following each dose. The 1993 ERS guideline [1] recommended using the "lowest technically satisfactory FEV1" at both baseline and later intervals; however, the subsequent ATS statement [3] recommended the highest FEV1. The latter is consistent with normal spirometry practice and avoids the problem that a submaximal inhalation (especially if the FVC is not measured) can give a falsely low FEV1 that appears technically satisfactory. The repeatability criteria of traditional spirometric measurements may not apply to tests performed after the administration of 
methacholine since deep inspiration can cause bronchodilation [56, 57]. Failure to meet repeatability standards should be used only to assist interpretation and not to exclude data from analysis.

\section{Forced inspiratory manoeuvres}

Patients with inducible laryngeal obstruction (ILO), including paradoxical vocal cord motion, or other causes of variable extrathoracic obstruction are not uncommon and often have a history suggesting asthma, leading to referral for BCT when this diagnosis is either considered or questioned. If inspiratory obstruction is suspected, or if inspiratory stridor is noted during the exam or following the final dose of methacholine, perform at least three full spirograms which include forced inspiratory vital capacity (FIVC) manoeuvres. ILO may be revealed as spontaneous or MCT-induced limitation of forced inspiratory flow resulting in a plateau, saw-toothing or irregularity in flow on the FIVC curves. In the case of exercise-induced laryngeal obstruction, a BCT with exercise may need to be done together with laryngoscopy in order to make a proper diagnosis [80, 81].

\section{Other methods}

Alternative methods of quantifying the response to challenge agents have been proposed, including airway resistance measurement by body plethysmography [82, 83] and forced oscillation [84, 85], but there is substantially less supporting research and standardisation; hence, these methods are beyond the scope of these guidelines. These may have a role with BCT in young children as addressed in an ATS/ERS statement on preschool pulmonary function testing [86]. Additional studies are needed to assess the value and interpretation of results using such methods.

\section{Data presentation}

The results are reported as a percentage decrease in FEV1 from the post-diluent FEV1 (or pre-challenge baseline if a diluent step is not used) in relationship to the calculated final dose. Data should be presented for each step in the protocol, including the post-bronchodilator spirometry. At a minimum, all of the elements in the sample MCT report in Appendix F of the supplementary material should be included, including volume-time or flow-volume curves. The expected pulmonary deposition of methacholine (delivered dose) for each concentration is calculated based on the time of inhalation, the particle size distribution (to estimate the respirable fraction), the rate of output and the respiratory duty cycle (TI/TTOT), which may be assumed to be $0.4[87,88]$. The PD20 (expressed as $\mu \mathrm{g}$ ) may be used to summarise the results for clinical purposes. Unless stated otherwise, it may be assumed that the PD20 is calculated from change in FEV1.

If FEV1 does not fall by at least $20 \%$ following the highest dose, then PD20 should be reported as "greater than the final dose given". Do not extrapolate beyond the final dose. If FEV 1 falls by $>20 \%$ following inhalation of the diluent, a PD20 is not reported. Instead, state "there was a significant decrease in lung function following inhalation of the diluent and methacholine was not given".

For manual graphic calculation of $\mathrm{PD}_{20}$, the change in FEV1 as a percentage of the control value may be plotted on the ordinate against log dose on the abscissa. For numerical calculation, see Appendix $\mathrm{E}$ of the supplementary material.

\section{Interpretation of direct bronchial challenge tests}

Direct airway challenges with methacholine are proposed as a diagnostic aid, to increase or decrease the probability of asthma. Evaluation of the test performance is hampered by the lack of an independent gold standard for objective confirmation of asthma. Nevertheless, the following approach is recommended.

The optimal diagnostic value of methacholine challenge testing occurs when the pre-test probability of asthma is $30-70 \%$ [89]. Current symptoms consistent with asthma increase the pre-test probability of this diagnosis (figure 2). Methacholine challenge testing is more useful in excluding a diagnosis of asthma than in establishing one because its negative predictive value, when respiratory symptoms are present, is greater than its positive predictive value.

The cut-point for defining normal versus abnormal methacholine/histamine PC20 was arbitrarily chosen to be highly sensitive and originally set at $8 \mathrm{mg} \cdot \mathrm{mL}^{-1}$ for the 2 -min tidal breathing method [51, 90]. Given the technical imprecision of the test, this cut-point was expanded in the 1999 ATS guideline to \pm 1 doubling dilution/concentration $\left(4-16 \mathrm{mg} \cdot \mathrm{mL}^{-1}\right)$; this range was suggested as indicating borderline AHR [3]. The arbitrary categorisation of AHR is outlined in table 6 for both $\mathrm{PC} 20$ in $\mathrm{mg} \cdot \mathrm{mL}^{-1}$ (when using the English Wright 2-min tidal protocol) and PD20 in $\mu$ g (when using any other nebuliser or protocol with the delivered dose calculated as described herein).

The sensitivity and specificity of any BCT will vary considerably with the population tested, e.g. a clinically symptomatic group versus a general population; however a few general statements can be made. In a 
FIGURE 2 Curves illustrating approximate pre-test and post-test probability of asthma after a methacholine challenge test. The approximations are presented as examples to illustrate the relationships and principles of decision analysis. Reproduced and modified from [3] with permission.

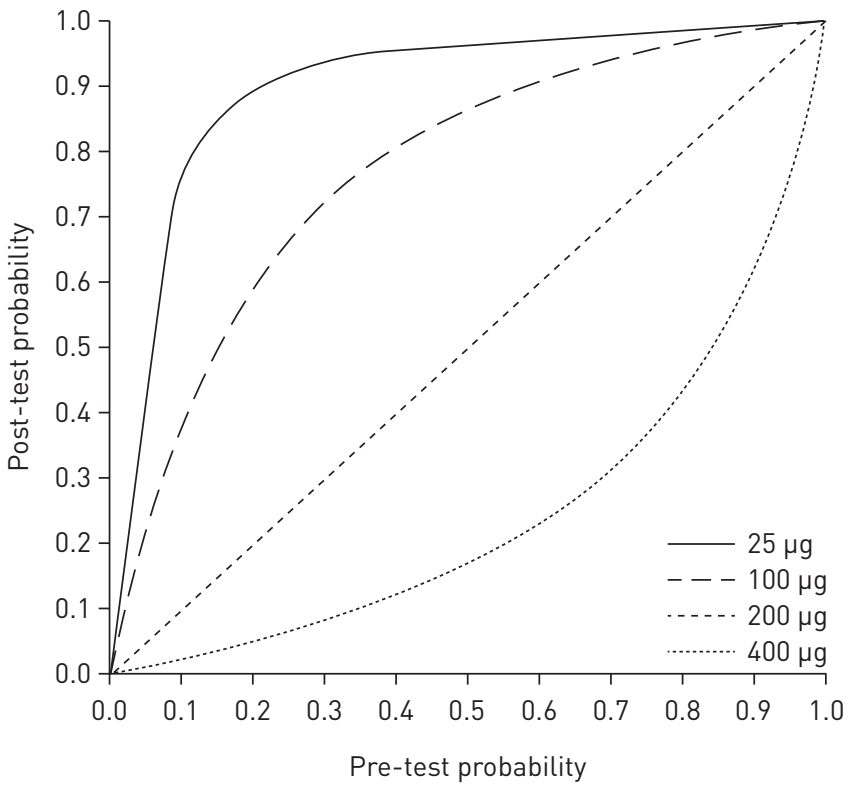

\begin{tabular}{|c|c|c|}
\hline PD20 $\mu \mathrm{mol}(\mu \mathrm{g})$ & $\mathrm{PC}_{20} \mathrm{mg} \cdot \mathrm{mL}^{-1}$ & Interpretation \\
\hline$>2(>400)$ & $>16$ & Normal \\
\hline $0.5-2.0(100-400)$ & $4-16$ & Borderline AHR \\
\hline $0.13-0.5(25-100)$ & $1-4$ & Mild AHR \\
\hline $0.03-0.13(6-25)$ & $0.25-1$ & Moderate AHR \\
\hline$<0.03(<6)$ & $<0.25$ & Marked AHR \\
\hline
\end{tabular}

PD20: provocative dose causing a $20 \%$ fall in forced expiratory volume in $1 \mathrm{~s}$ (FEV1); $\mathrm{PC}_{20}$ : provocative concentration causing a $20 \%$ fall in FEV1; AHR: airway hyperresponsiveness. Information from [3].

clinical population the test is highly sensitive, such that a normal (negative) methacholine challenge (PC20 $>16 \mathrm{mg} \cdot \mathrm{mL}^{-1}, \mathrm{PD}_{20}>400 \mu \mathrm{g}$ or $2 \mu \mathrm{mol}$ ) effectively excludes current asthma if symptoms were present within the previous few days $[91,92]$. False-negative tests should be infrequent if testing is done at a time of current or recent symptoms. False-negative methacholine challenges do occur in a very small population of elite athletes who may exhibit positive indirect airway responsiveness yet negative direct (MCT) airway responsiveness [92]. One other important cause of a false-negative methacholine challenge is the failure to withhold both specific and functional antagonist medications for the appropriate duration. False-positive challenges (i.e. positive methacholine challenges in subjects without asthma symptoms) occur in a significant proportion of individuals, e.g. in a group of young adults with no history or symptoms of asthma, $4.5 \%$ had a positive test result at a cut-point of $8 \mathrm{mg} \cdot \mathrm{mL}^{-1}(\mathrm{PD} 20200 \mu \mathrm{g})$ and $21 \%$ at a cut-point of $16 \mathrm{mg} \cdot \mathrm{mL}^{-1}$ (PD20 $400 \mu \mathrm{g}$ ) [93, 94]. A methacholine $\mathrm{PC} 20<1 \mathrm{mg} \cdot \mathrm{mL}^{-1}(\mathrm{PD} 20<25 \mu \mathrm{g})$ is highly specific (but very insensitive) for a diagnosis of asthma [93]. Most MCT results have PC20 values between 1 and $16 \mathrm{mg} \cdot \mathrm{mL}^{-1}$ (PD20 25-400 $\mu \mathrm{g}$ ), and are intermediate in terms of sensitivity and specificity. The probability that a positive MCT reflects asthma will increase the lower the PC20 or PD20 [93], the higher the pre-test probability of asthma [3] and the more closely that the methacholine-induced symptoms mimic the naturally occurring symptoms.

In summary, the major value of direct airway responsiveness challenge is to exclude a diagnosis of current asthma. Positive challenges are consistent with but not entirely diagnostic of asthma and must be interpreted in conjunction with the presence of other features of asthma or other respiratory diseases.

\section{References}

1 Sterk PJ, Fabbri LM, Quanjer PH, et al. Airway responsiveness. Standardized challenge testing with pharmacological, physical and sensitizing stimuli in adults. Eur Respir J 1993; 6: Suppl. 16, 53-83.

2 Joos GF, O'Connor B, Anderson SD, et al. Indirect airway challenges. Eur Respir J 2003; 21: 1050-1068. 
3 Crapo RO, Casaburi R, Coates AL, et al. Guidelines for methacholine and exercise challenge testing - 1999. Am J Respir Crit Care Med 2000; 161: 309-329.

4 Maurer M, Simonett D, Brutsche MH. Challenge of exercise-induced asthma and exercise-induced bronchoconstriction. Exp Rev Respir Med 2009; 3: 13-19.

5 Leuppi JD, Kuhn M, Comminot C, et al. High prevalence of bronchial hyperresponsiveness and asthma in ice hockey players. Eur Respir J 1998; 12: 13-16.

6 An SS, Bai TR, Bates JHT, et al. Airway smooth muscle dynamics: a common pathway of airway obstruction in asthma. Eur Respir J 2007; 29: 834-860.

7 Paré PD, McParland BE, Seow CY. Structural basis for exaggerated airway narrowing. Can J Physiol Pharmacol 2007; 7: 653-658.

8 Bossé Y, Riesenfeld EP, Paré PD, et al. It's not all smooth muscle: non-smooth-muscle elements in control of resistance to airflow. Annu Rev Physiol 2010; 72: 437-462.

9 Coates AL, Leung K, Dell SD. Developing alternative delivery systems for methacholine challenge tests. J Aerosol Med Pulmon Drug Deliv 2014; 27: 66-70.

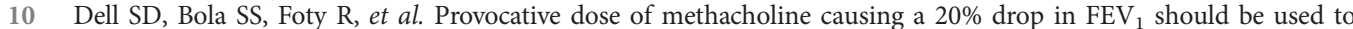
interpret methacholine challenge tests with modern nebulizers. Ann Am Thorac Soc 2015; 12: 357-363.

11 El-Gammal A, Killian KJ, Scime TX, et al. Comparison of the provocative concentration of methacholine causing a $20 \%$ fall in $\mathrm{FEV}_{1}$ between the AeroEclipse II breath-actuated nebulizer and the Wright nebulizer in adult subjects with asthma. Ann Am Thorac Soc 2015; 12: 1039-1043.

12 Van Den Berge M, Meijer RJ, Kerstjens HA, et al. $\mathrm{PC}_{20}$ adenosine $5^{\prime}$-monophosphate is more closely associated with airway inflammation in asthma than $\mathrm{PC}_{20}$ methacholine. Am J Respir Crit Care Med 2001; 163: 1546-1550.

13 Anderson SD, Brannan JD. Methods for "indirect" challenge tests including exercise, eucapnic voluntary hyperpnea and hypertonic aerosols. Clin Rev Allergy Immunol 2003; 24: 27-54.

14 Pedersen L, Winther S, Backer V, et al. Airway responses to eucapnic hyperpnea, exercise, and methacholine in elite swimmers. Med Sci Sports Exerc 2008; 40: 1567-1572.

15 Vandenplas O, Suojalehto H, Aasen TB. Specific inhalation challenge in the diagnosis of occupational asthma: consensus statement. Eur Respir J 2014; 43: 1573-1587.

16 Cooper BG. An update on contraindications for lung function testing. Thorax 2011; 66: 714-723.

17 Ramsdale EH, Morris MM, Roberts RS, et al. Bronchial responsiveness to methacholine in chronic bronchitis: relationship to airflow obstruction and cold air responsiveness. Thorax 1984; 39: 912-918.

18 Miller MR, Hankinson JL, Brusasco V, et al. Standardisation of spirometry. Eur Respir J 2005; 26: 319-338.

19 Enright PL, Lebowitz MD, Cockcroft DW. Physiological measures: pulmonary function tests. Asthma outcomes. Am J Respir Crit Care Med 1994; 149: S9-S18.

20 Cockcroft DW, Swystun VA, Bhagat RG. Interaction of inhaled beta 2 agonist and inhaled corticosteroid on airway responsiveness to allergen and methacholine. Am J Respir Crit Care Med 1995; 152: 1485-1489.

21 Ahrens RC, Bonham AC, Maxwell GA, et al. A method for comparing the peak intensity and duration of action of aerosolized bronchodilators using bronchoprovocation with methacholine. Am Rev Respir Dis 1984; 129: 903-906.

22 Greenspon LW, Morrissey WL. Factors that contribute to inhibition of methacholine-induced bronchoconstriction. Am Rev Respir Dis 1986; 133: 735-739.

23 Derom EY, Pauwels RA, Van Der Straeten MEF. The effect of inhaled salmeterol on methacholine responsiveness in subjects with asthma up to 12 hours. J Allergy Clin Immunol 1992; 89: 811-815.

24 Cockcroft DW, Swystun VA. Effect of single doses of S-salbutamol, R-salbutamol, racemic salbutamol, and placebo on the airway response to methacholine. Thorax 1997; 52: 845-848.

25 O'Byrne PM, van der Linde J, Cockcroft DW, et al. Prolonged bronchoprotection against inhaled methacholine by inhaled BI 1744, a long acting $\beta_{2}$-agonist, in patients with mild asthma. J Allergy Clin Immunol 2009; 124: 1217-1221.

26 Crimi N, Palermo F, Oliveri R, et al. Protective effects of inhaled ipratropium bromide on bronchoconstriction induced by adenosine and methacholine in asthma. Eur Respir J 1992; 5: 560-565.

27 Wilson NM, Coe C, Barnes PJ. Duration of protection by oxitropium bromide against cholinergic challenge. Eur J Respir Dis 1987; 71: 455-458.

28 Illamperuma C, Davis BE, Fenton ME, et al. Duration of bronchoprotection of inhaled ipratropium against inhaled methacholine. Ann Allergy Asthma Immunol 2009; 102: 438-439.

29 O'Connor BJ, Towse LJ, Barnes PJ. Prolonged effect of tiotropium bromide on methacholine-induced bronchoconstriction in asthma. Am J Respir Crit Care Med 1996; 154: 876-880.

30 Blais CM, Davis BE, Cockcroft DW. Duration of bronchoprotection of the long-acting muscarinic antagonists tiotropium \& glycopyrronium against methacholine induced bronchoconstriction in mild asthmatics. Respir Med 2016; 118: 96-101.

31 Janssen LJ, Gauvreau GM, Killian KJ, et al. The effects of repeated bronchoprovocation on FEV $\mathrm{F}_{1}$ in subjects with asthma. Ann Am Thorac Soc 2015; 12: 1589-1591.

32 Chua HL, Collis GG, Newbury AM, et al. The influence of age on aerosol deposition in children with cystic fibrosis. Eur Respir J 1994; 7: 2185-2191.

33 Sherman CB, Kern DG, Corwin RW, et al. A clinical and structural comparison of industrial methacholine and provocholine. Chest 1994; 105: 1095-1097.

34 Hayes RD, Beach JR, Rutherford DM, et al. Stability of methacholine chloride solutions under different storage conditions over a 9 month period. Eur Respir J 1998; 11: 946-948.

35 Miller MR, Crapo RO, Hankinson JL, et al. General considerations for lung function testing. Eur Respir J 2005; 26: $153-161$.

36 Cockcroft DW, Killian DN, Mellon JJA, et al. Protective effect of drugs on histamine-induced asthma. Thorax 1977; 32: 429-437

37 Ryo UY, Kang B, Townley RG. Cromolyn therapy in patients with bronchial asthma. Effect on inhalation challenge with allergen, histamine, and methacholine. JAMA 1976; 236: 927-931.

38 Patel KR. Sodium cromoglycate in histamine and methacholine reactivity in asthma. Clin Allergy 1984; 14: 143-145. 

Can Respir J 2005; 12: 26-28. Gauvreau GM, Doctor J, Watson RM, et al. Effects of inhaled budesonide on allergen-induced airway responses and airway inflammation. Am J Respir Crit Care Med 1997; 154: 1267-1271.

41 Yurach MT, Davis BE, Cockcroft DW. The effect of caffeinated coffee on airway response to methacholine and exhaled nitric oxide. Respir Med 2011; 110: 1606-1610.

42 Ferrari M, Olivieri M, Lampronti G, et al. Effect of once daily and twice daily sustained release theophylline formulations on daytime variation of bronchial hyperresponsiveness in asthmatic patients. Thorax 1997; 52: 969-974.

43 Woenne R, Kattan M, Orange RP, et al. Bronchial hyperreactivity to histamine and methacholine in asthmatic children after inhalation of SCH 1000 and chlorpheniramine maleate. J Allergy Clin Immunol 1978; 62: 119-124.

44 Juniper EF, Kline PA, Roberts RS, et al. Airway responsiveness to methacholine during the natural menstrual cycle and the effect of oral contraceptives. Am Rev Respir Dis 1987; 135: 1039-1042.

45 Duval NJ, Lahren KM, O’Neil KM. Effect of influenza vaccine on bronchoprovocation testing in normal subjects. Chest 1994; 106: 750-752.

46 Cockcroft DW, Davis BE, Roh Y, et al. Effect of ingested $\mathrm{H}_{1}$ antihistamines on methacholine challenge. J Allergy Clin Immunol 2015; 135: 579-580.

47 Finnerty JP, Holgate ST, Rihoux JP. The effect of 2 weeks treatment with cetirizine on bronchial reactivity to methacholine in asthma. Br J Clin Pharmacol 1990; 29: 79-84.

48 Dotar DE, Davis BE, Cockcroft DW. Dose versus concentration of methacholine. Ann Allergy 1999; 83: $229-239$.

49 Schulze J, Roswich M, Riemer C, et al. Methacholine challenge - comparison of an ATS protocol to a new rapid single concentration technique. Respir Med 2009; 103: 1898-1903.

50 Drotar DE, Davis BE, Cockcroft DW. Dose versus concentration of methacholine. Ann Allergy 1999; 83: 229-230.

51 Juniper EF, Frith PADC, Cockcroft DW, et al. Reproducibility and comparison of responses to inhaled histamine and methacholine: relationship to minimum treatment to control symptoms of asthma. Thorax 1978; 33: 705-710.

52 Coates $\mathrm{AL}$, Dell SD, Cockcroft DW, et al. The $\mathrm{PD}_{20}$ but not the $\mathrm{PC}_{20}$ in a methacholine challenge test is device independent. Ann Asthma Allergy Immunol 2017; 118: 508-509.

53 Cockcroft DW, Davis BE, Todd DC, et al. Methacholine challenge: comparison of two methods. Chest 2005; 127: 839-844.

54 Prieto L, Ferrer A, Pérez-Francés C. Effect of challenge method on sensitivity, reactivity and maximal response to methacholine. Ann Allergy Asthma Immunol 2006; 97: 175-181.

55 Cockcroft DW, Davis BE. The bronchoprotective effect of inhaling methacholine by using total lung capacity inspirations has a marked influence on the interpretation of the test result. J Allergy Clin Immunol 2006; 117: 1244-1248.

56 Allen ND, Davis BE, Hurst TS, et al. Difference between dosimeter and tidal breathing methacholine challenge: contributions of dose and deep inspiration bronchoprotection. Chest 2005; 128: 4018-4023.

57 Cockcroft DW, Davis BE. Mechanisms of airway hyperresponsiveness. J Allergy Clin Immunol 2006; 118: 551-559.

58 Prieto L, Lopez V, Llusar R, et al. Differences in the response to methacholine between the tidal breathing and dosimeter methods: influence of the dose of bronchoconstrictor agent delivered to the mouth. Chest 2008; 134: 699-703.

59 Todd DC, Davis BE, Hurst TS, et al. Dosimeter methacholine challenge: comparison of maximal versus submaximal inhalations. J Allergy Clin Immunol 2004; 114: 517-519.

60 Brain JD, Valberg PA. Deposition of aerosol in the respiratory tract. Am Rev Respir Dis 1979; 120: 1325-1373.

61 Coates AL, MacNeish CF, Lands LC, et al. Factors influencing the rate of drug output during the course of wet nebulization. J Aerosol Med 1998; 11: 101-111.

62 Coates AL, MacNeish CF, Meisner D, et al. The choice of jet nebulizer, nebulizing flow and the addition of Ventolin Respiratory Solution affects tobramycin aerosols used in cystic fibrosis. Chest 1997; 111: 1206-1212.

63 Cockcroft DW, Hurst TS, Gore BP. Importance of evaporative water losses during standardized nebulized inhalation provocation tests. Chest 1989; 96: 505-508.

64 Cockcroft DW, Berscheid BA. Standardization of inhalation provocation tests. Dose vs concentration of histamine. Chest 1982; 82: 572-575.

65 Cockcroft DW, Davis BE, Smycniuk AJ. Development of a methacholine challenge method to minimize methacholine waste. Chest 2003; 124: 1522-1525.

66 Parker CD, Bilbo RE, Reed CE. Methacholine aerosol as test for bronchial asthma. Arch Intern Med 1965; 115: 452-548.

67 Chatham M, Bleecker ER, Norman P, et al. A screening test for airways reactivity. An abbreviated methacholine inhalation challenge. Chest 1982; 82: 15-18.

68 Schmidt LE, Thorne PS, Watt JL, et al. Is an abbreviated bronchial challenge with histamine valid? Chest 1992; 101: 141-145.

69 Sovijärvi ARA, Malmberg LP, Reinkainen K, et al. A rapid dosimetric method with controlled tidal breathing for histamine challenge: repeatability and distribution of bronchial reactivity in a clinical material. Chest 1993; 104: 164-170.

70 Jorres RA, Nowak D, Kirsten D, et al. A short protocol for methacholine provocation testing adapted to the Rosenthal-Chai dosimeter technique. Chest 1997; 111: 866-869.

71 Wanger JS, Ikle DN, Irvin CG. Airway responses to a diluent used in the methacholine challenge test. Ann Allergy Asthma Immunol 2001; 86: 277-282.

72 Ho SL, Kwong WTJ, Coates AL. Evaluation of four breath-enhanced nebulizers for home use. J Aerosol Med 2001; 14: $467-475$.

73 Katz SL, Ho SL, Coates AL. Nebulizer choice for inhaled colistin treatment in cystic fibrosis. Chest 2001; 119: 250-255.

74 Katz SL, Adatia I, Louca E, et al. Nebulized therapies for childhood pulmonary hypertension: an in vitro model. Pediatr Pulmonol 2006; 41: 666-673.

75 Leung K, Louca E, Coates AL. Comparison of breath enhanced to breath actuated nebulizers for rate, consistency and efficiency. Chest 2004; 26: 1619-1627.

76 Kwong WTJ, Ho SL, Coates AL. Comparison of nebulized particle size distribution with Malvern laser diffraction analyzer versus Andersen cascade impactor and low-flow Marple personal cascade impactor. J Aerosol Med 2000; 13: 303-314. 
77 Mitchell JP, Nagel MW, Nichols S, et al. Laser diffractometry as a technique for the rapid assessment of aerosol particle size from inhalers. J Aerosol Med 2006; 19: 409-433.

78 Kwong MS, Egan EA, Notter RH, et al. Double-blind clinical trial of calf lung surfactant extract for the prevention of hyaline membrane disease in extremely premature infants. Pediatrics 1985; 76: 585-592.

79 Finlay WH, Stapleton KW. Undersizing of droplets from a vented nebulizer caused by aerosol heating during transit through an Anderson impactor. J Aerosol Sci 1999; 30: 105-109.

80 Nielsen EW, Hull JH, Backer V. High prevalence of exercise-induced laryngeal obstruction in athletes. Med Sci Sports Exerc 2013; 45: 2030-2035.

81 Tilles SA, Ayars AG, Picciano JF, et al. Exercise-induced vocal cord dysfunction and exercise-induced laryngomalacia in children and adolescents. Ann Allergy Immunol 2013; 111: 342-346.

82 Cockcroft DW, Berscheid BA. Measurement of responsiveness to inhaled histamine: comparison of FEV ${ }_{1}$ and $s G_{\text {aw. }}$ Ann Allergy 1983; 51: 377.

83 Habib MP, Paré PD, Engels LA. Variability of airways response to inhaled histamine in normal subjects. $J$ Appl Physiol 1979; 47: 51-58.

84 Wilson NM, Bridge P, Phagoo SB, et al. The measurement of methacholine responsiveness in 5 year old children: three methods compared. Eur Respir J 1995; 8: 364-370.

85 Klug B, Bisgaard H. Measurement of lung function in awake 2-4-year-old asthmatic children during methacholine challenge and acute asthma: a comparison of the impulse oscillation technique, the interrupter technique, and transcutaneous measurement of oxygen versus whole-body plethysmography. Pediatr Pulmonol 1996; 21: 290-300.

86 Beydon N, Davis SD, Lombardi E, et al. An official American Thoracic Society/European Respiratory Society statement: pulmonary function testing in preschool children. Am J Respir Crit Care Med 2007; 175: 1304-1343.

87 Coates AL, MacNeish CF, Allen PD, et al. Do sinusoidal models of respiration accurately reflect the respiratory events of patients breathing on nebulizers? J Aerosol Med 1999; 12: 265-273.

88 Coates AL, Allen PD, MacNeish CF, et al. Effect of size and disease on estimated deposition of drugs administered using jet nebulization in children with cystic fibrosis. Chest 2001; 119: 1123-1130.

89 Perpiñá M, Pellicer C, de Diego A, et al. Diagnostic value of the bronchial provocation test with methacholine in asthma. A Bayesian analysis approach. Chest 1993; 104: 149-154.

90 Cockcroft DW, Killian DN, Mellon JJA, et al. Bronchial reactivity to inhaled histamine: a method and clinical survey. Clin Allergy 1997; 7: 325-243.

91 Cockcroft DW, Hargreaves FE. Airway hyperresponsiveness: relevance of random population data to clinical usefulness. Am Rev Respir Dis 1990; 142: 497-500.

92 Holzer K, Anderson SD, Douglass JA. Exercise in elite summer athletes: challenges for diagnosis. J Allergy Clin Immunol 2002; 110: 374-380.

93 Cockcroft DW, Murdock KY, Berscheid BA, et al. Sensitivity and specificity of histamine $\mathrm{PC}_{20}$ determination in a random selection of young college students. J Allergy Clin Immunol 1992; 89: 23-30.

94 Cockcroft DW, Davis BE. Histamine and methacholine challenge cut points. Ann Allergy Asthma Immunol 2010; 104: 450-451. 